\title{
QUEBRA DE DORMÊNCIA EM SEMENTES DE Schefflera morototoni (Aubl.)
} Maguire et al.

Marcella Karoline Cardoso Vilarinho ${ }^{1}$, Vitor Hugo Dantas Sales ${ }^{2}$, Jeyson Conceição Nascimento $^{3}$, Daniela Soares Alves Caldeira ${ }^{4}$, Wellington Ribeiro de Souza ${ }^{5}$

${ }^{1}$ Professora Mestre do curso de Agronomia da UNEMAT, Cáceres-MT, Brasil. Email: marcellakarolinecv@hotmail.com

${ }^{2}$ Bacharel em Agronomia da Universidade do Estado de Mato Grosso (UNEMAT), Cáceres-MT, Brasil.

${ }^{3}$ Bacharel em Agronomia da Universidade do Estado de Mato Grosso (UNEMAT), Cáceres-MT, Brasil.

${ }^{4}$ Professora Doutora do curso de Agronomia da UNEMAT, Cáceres-MT, Brasil.

${ }^{5}$ Mestrando, Bacharel em Agronomia da Universidade do Estado de Mato Grosso (UNEMAT), Cáceres-MT, Brasil.

\section{Recebido em: 06/04/2019 - Aprovado em: 10/06/2019 - Publicado em: 30/06/2019 DOI: 10.18677/EnciBio_2019A115}

\begin{abstract}
RESUMO
A espécie Schefflera morototoni (Aubl.) Maguire, Steyerm. \& Frodin, pertence à família Araliaceae, conhecida popularmente como morototó. A espécie apresenta baixa taxa de germinação, supostamente por seu tegumento ser rígido, ou problemas relacionados ao embrião. Diante disso, objetivou-se avaliar a quebra de dormência de sementes de Schefflera morototoni. O estudo foi conduzido no Laboratório de Sementes do curso de Agronomia, na Universidade do Estado de Mato Grosso, campus Cáceres - MT. Anterior a instalação do experimento as sementes apresentaram uma média de $6,54 \%$ de teor de água. O delineamento experimental adotado foi inteiramente casualizado, com 11 tratamentos e 4 repetições. Os tratamentos usados foram: $100^{\circ} \mathrm{C}$ por 1 segundo e em água com temperatura ambiente, $100^{\circ} \mathrm{C}$ por 10 segundos e em água com temperatura ambiente, $100^{\circ} \mathrm{C}$ por 1 segundo e em água gelada, $100^{\circ} \mathrm{C}$ por 10 segundos e em água gelada, $100^{\circ} \mathrm{C}$ por 1 segundo + hipoclorito/ 1 minuto, $100^{\circ} \mathrm{C}$ por 10 segundos + hipoclorito/ 1 minuto, $100^{\circ} \mathrm{C}$ por 1 segundo, $100^{\circ} \mathrm{C}$ por 10 segundos, ácido acético por 10 minutos, ácido acético por 15 minutos e testemunha. Foram avaliados o índice de velocidade de germinação, índice de germinação e primeira contagem de germinação. Após os 42 dias de instalação do experimento, observou-se que, para todos os parâmetros avaliados não ocorreu germinação em nenhum dos tratamentos propostos. Os tratamentos usados na quebra de dormência de sementes de Schefflera morototoni não mostraram eficiência, possivelmente o tempo de armazenamento e o teor de água das sementes influenciaram para que as mesmas não germinassem.
\end{abstract}

PALAVRAS-CHAVE: germinação, morototó, qualidade das sementes. 


\title{
DORMANCY BREAKING OF SEEDS OF SCHEFFLERA MOROTOTONI (Aubl.) Maguire et al.
}

\begin{abstract}
The species Schefflera morototoni (Aubl.) Maguire, Steyerm. \& Frodin, belongs to the family Araliaceae, popularly known as morototó. The species presents a low germination rate, supposedly due to its integument being rigid, or embryo related problems. Therefore, the objective of this study was to evaluate the seed dormancy breaking of Schefflera morototoni. The study was conducted in the Laboratory of Seeds of the Agronomy course at the State University of Mato Grosso, Cáceres - MT campus. Before the installation of the experiment the seeds presented an average of $6.54 \%$ of water content. The experimental design adopted was completely randomized, with 11 treatments and 4 repetitions. The treatments used were: $100^{\circ} \mathrm{C}$ for 1 second and in ambient temperature water, $100^{\circ} \mathrm{C}$ for 10 seconds and in ambient temperature water, $100^{\circ} \mathrm{C}$ for 1 second and in cold water, $100^{\circ} \mathrm{C}$ for 10 seconds and in cold water, $100^{\circ} \mathrm{C}$ for 1 second + hypochlorite $/ 1$ minute , $100^{\circ} \mathrm{C}$ for 10 seconds + hypochlorite $/ 1$ minute, $100^{\circ} \mathrm{C}$ for 1 second, $100^{\circ} \mathrm{C}$ for 10 seconds, acetic acid for 10 minutes, acetic acid for 15 minutes and control seeds. The germination speed index, the germination index and the first germination count were evaluated. After the 42 days of the experiment, it was observed that, for all evaluated parameters, no germination occurred in any of the proposed treatments. The treatments used to evaluate the dormancy breaking of Schefflera morototoni seeds were not efficient, possibly the storage time and the water content influenced the seeds not to germinate.
\end{abstract}

KEYWORDS: germination, morototó, seed quality.

\section{INTRODUÇÃO}

A espécie Schefflera morototoni (Aubl.) Maguire, Steyerm. \& Frodin, pertencente à família Araliaceae, e é conhecida popularmente como: mandiocão, morototó ou caixeta. Encontra-se em diferentes tipologias florestais, como em florestas altas e densas de terra firme, capoeiras, capoeirões, margens de estradas e savanas em quase todo território brasileiro, exceto nos estados do Piauí e Tocantins (OHASHI; LEÃO, 2005; CARVALHO, 2014).

Segundo Liegel (1990), esta espécie se desenvolve bem em vários tipos de solos, especialmente aqueles abandonados depois do uso agrícola. Estudos relatam que a espécie pode atingir altura de $35 \mathrm{~m}$ e $120 \mathrm{~cm}$ de DAP (diâmetro à altura do peito), na Amazônia. A espécie é altamente indicada para arborização urbana e recomposição de áreas alteradas pelo seu rápido crescimento e, por ser fonte de alimento para uma grande diversidade de animais. Sua madeira pode ser usada na indústria madeireira para produção de compensados, caibros, vigas e pisos (FERNANDES et al., 2019).

Ainda não se sabe com exatidão se as sementes de morototó são consideradas ortodoxas ou intermediárias, sendo assim, necessários estudos que aprofundem sobre a influência do armazenamento na qualidade dessa espécie (OHASHI E LEÃO, 2005). Sementes ortodoxas são sementes que mantêm por maior tempo sua qualidade fisiológica quando armazenadas com baixos teores de água e sob baixas temperaturas, quando se eleva o teor de água nessas sementes, tendem a acelerar a ação da deterioração das mesmas em razão do aumento da atividade respiratória, consumo de reservas, liberação de calor e proliferação de microrganismos. Existem espécies ortodoxas que germinam mesmo com $5 \%$ de teor 
de água (LUCAS et al., 2018). Já as intermediárias possuem uma pequena resistência a baixas temperaturas, a um curto período, porém certa tolerância à dessecação, apresentando comportamento intermediário entre as sementes ortodoxas e recalcitrantes, com baixo teor de água.

Ainda segundo os autores, a espécie apresenta baixa taxa de germinação, supostamente por seu tegumento ser rígido ou problemas relacionados ao embrião. Grande quantidade das espécies florestais nativas precisa de tratamentos que rompam a dormência da semente para que então se inicie germinação, mesmo em condições favoráveis (ABDO; FABRI, 2015).

A característica de certas plantas retardarem a germinação de suas sementes através do processo de dormência, até que as condições do ambiente estejam adequadas, é um importante mecanismo de sobrevivência, que permite distribuir sua germinação no tempo e espaço (MEDEIROS, 2001).

No entanto, essa característica passa a ser um transtorno quando as sementes são usadas na produção de mudas, em razão da desuniformidade de germinação ao longo tempo, prejudicando o processo produtivo (LUCAS et al., 2018). Ainda, a exploração inadequada, desmatamentos e cortes indevidos visando a utilização de sua madeira, ocasionam reduções na população da espécie, tornando cada vez mais difícil sua produção.

Existem diversos métodos indicados para se proceder a quebra de dormência em espécies florestais e dentre os mais utilizados, citam-se as escarificações mecânica e química, submersão em água em ponto de ebulição e pré-resfriamento (PEREIRA et al., 2015; SAMPAIO et al., 2015; ABREU et al., 2017).

Diante disso, o trabalho objetivou avaliar a quebra de dormência de sementes de Schefflera morototoni.

\section{MATERIAL E MÉTODOS}

O estudo foi conduzido no Laboratório de Sementes do curso de Agronomia, na Universidade do Estado de Mato Grosso (UNEMAT), campus Cáceres - MT. A espécie florestal utilizada foi o morototó (Schefflera morototoni (Aubl.) Maguire et al.). A obtenção das sementes se deu de forma comercial, por meio de uma empresa especializada em comércio de sementes localizada no município de Birigui - SP. Antes da utilização das sementes as mesmas ficaram armazenadas por um período de um ano e nove meses, sob temperatura de 10 a $12{ }^{\circ} \mathrm{C}$ em geladeira do tipo doméstica.

No momento em que o experimento foi instalado, as sementes apresentaram uma média de $6,54 \%$ de teor de água, valor obtido através de teste realizado de acordo com metodologia da RAS, pelo método de estufa à $105 \pm 3{ }^{\circ} \mathrm{C}$ por 24 horas (Brasil, 2009). O delineamento experimental adotado foi inteiramente casualizado (DIC) com 11 tratamentos e 4 repetições com 25 sementes cada. Testou-se os seguintes tratamentos:

QUADRO 1 - Tratamentos utilizados na avaliação da quebra de dormência em sementes de Schefflera morototoni.

\begin{tabular}{|c|c|c|}
\hline \multicolumn{3}{|c|}{ Tratamentos } \\
\hline & $\mathbf{H} 20$ & Tempo + Substância \\
\hline $\mathrm{T} 1$ & $\mathrm{H} 2 \mathrm{O} 100^{\circ} \mathrm{C}$ & 1 segundo $+\mathrm{H} 2 \mathrm{O}$ ambiente \\
\hline $\mathrm{T} 2$ & $\mathrm{H} 2 \mathrm{O} 100^{\circ} \mathrm{C}$ & 10 segundos $+\mathrm{H} 2 \mathrm{O}$ ambiente \\
\hline
\end{tabular}




\begin{tabular}{|c|c|c|}
\hline T3 & $\mathrm{H} 2 \mathrm{O} 100 \stackrel{\circ}{\mathrm{C}}$ & 1 segundo $+\mathrm{H} 2 \mathrm{O}$ gelada \\
\hline T 4 & $\mathrm{H} 2 \mathrm{O} 100^{\circ} \mathrm{C}$ & 10 segundos $+\mathrm{H} 2 \mathrm{O}$ gelada \\
\hline T 5 & $\mathrm{H} 2 \mathrm{O} 100 \stackrel{\circ}{ } \mathrm{C}$ & $\begin{array}{l}1 \text { segundo }+ \text { hipoclorito }(2,5 \%) / 1 \\
\text { minuto }\end{array}$ \\
\hline T 6 & $\mathrm{H} 2 \mathrm{O} 100 \stackrel{\circ}{ } \mathrm{C}$ & $\begin{array}{l}10 \text { segundos }+ \text { hipoclorito }(2,5 \%) / 1 \\
\text { minuto }\end{array}$ \\
\hline T 7 & $\mathrm{H} 2 \mathrm{O} 100 \stackrel{\circ}{\mathrm{C}}$ & 1 segundo \\
\hline T 8 & $\mathrm{H} 2 \mathrm{O} 100 \stackrel{\circ}{\mathrm{C}}$ & 10 segundos \\
\hline T9 & Ácido acético (6\%) & 10 minutos \\
\hline T 10 & Ácido acético $(6 \%)$ & 15 minutos \\
\hline T 11 & Testemunha & - \\
\hline
\end{tabular}
parâmetros:

Após 42 dias de instalação do experimento, foram avaliados os seguintes

Índice de germinação: dividiram-se as sementes em quatro repetições de 25 unidades cada. As contagens foram realizadas, considerando apenas germinadas as plântulas normais, obtendo-se a média das repetições, com os dados estabelecidos em percentagem de germinação. Primeira contagem de germinação: conduzido conforme a regra para análises de sementes, realizando após 42 dias após a semeadura (BRASIL, 2009). Índice de velocidade de germinação (IVG): o IVG conduziu-se através da contagem diária do número de plântulas germinadas até sua estabilização. O cálculo para o índice foi realizado conforme a fórmula proposta por Maguire (1962). Sementes umedecidas: concomitante as leituras de índice de velocidade de germinação foram realizadas a leitura diária de sementes visualmente entumecidas. Peso de mil sementes: obtido por meio da contagem aleatória e manual de 8 repetições de 100 sementes. Calculou-se a variância, desvio padrão e coeficiente de variação dos valores obtidos das pesagens, conduzido de acordo com a regra para análises de sementes (BRASIL, 2009).

Submeteram-se os dados à análise de variância, e as médias dos tratamentos através do teste de Tukey a $5 \%$, utilizando o programa estatístico SISVAR (FERREIRA, 2014).

\section{RESULTADOS E DISCUSSÃO}

O experimento foi conduzido até $042^{\circ}$ dia após a montagem do teste, período esse suficiente para o início da germinação, pois, de acordo com Cipriani et al. (2016), as sementes de morototó iniciam a germinação por volta do $36^{\circ}$ dia. Após esse tempo, não se observou germinação em nenhum dos tratamentos, impossibilitando, portanto, que todos os parâmetros relacionados ao índice de germinação, primeira contagem de germinação, índice de velocidade de germinação (IVG), e sementes umedecidas fossem avaliados.

As possíveis causas da não germinação podem ser devidas a diversos fatores, dentre eles, supõe-se que a ineficácia dos tratamentos, que no caso do presente estudo, foram voltadas à quebra de dormência do tegumento, podem ter gerado a negatividade dos resultados, embora existam trabalhos que demonstrem resultados, ainda que em índices reduzidos, a germinação de sementes dessa espécie quando submetidas a tratamentos relacionados à quebra de dormência do tegumento. 
Cipriani et al. (2016) trabalhando com tratamentos de hidróxido de sódio para a quebra de dormência de sementes de morototó, conseguiu um índice de $60 \%$ de germinação. Já Ohashi e Leão (2005) afirmam que o tratamento pré-germinativo para essa espécie, com submersão em água em ponto de ebulição por 5 minutos, seguida da submersão em água à temperatura ambiente por 12 horas, pode reduzir o período de germinação e resultar em germinação superior a 70\%, entre 25 e 45 dias.

Mesquita et al. (2016) trabalhando com sementes de Schefflera morototoni, avaliaram que o tratamento utilizando sementes que permaneceram no fruto em temperatura ambiente e retiradas somente no dia da montagem do experimento, apresentaram uma taxa de germinação de $2,5 \%$ após 68 dias de análise. Esse fato pode ser um indicativo de que as sementes necessitem de um período de tempo maior para que iniciem a germinação. Andrade et al. (1997) analisaram através de estudos, que a submersão de sementes de Bowdichia virgilioides em água em ebulição $\left(100{ }^{\circ} \mathrm{C}\right.$, por 1,2 e 3 minutos), produziu os maiores valores médios de sementes embebidas, porém produziu as menores porcentagens de germinação. Esses resultados se justificam pelo fato das sementes de algumas espécies arbóreas apresentarem dormência tegumentar (ROCHA et al., 2018).

Devido ao baixo índice germinativo encontrado também em diversos trabalhos, aliado a dormência do tegumento, pode-se supor que as sementes de morototó também possuem dormência fisiológica, fato esse que explicaria a não germinação no estudo em questão. A dormência fisiológica está relacionada com a presença de inibidores químicos no embrião, o desbalanço hormonal ou quando o embrião é incapaz de superar as barreiras físicas e/ou mecânicas ocasionadas pelos tecidos adjacentes à semente, podendo ocorrer dificuldades na germinação. Segundo Bispo e Ferreira (2018) tratamentos para a quebra de dormência de sementes de Annona crassiflora Mart., com uso de ácido giberélico podem gerar um melhor índice de germinação.

Além da dormência, outro fator contribuinte ao resultado do presente estudo pode estar relacionado ao tempo de armazenamento das sementes. Segundo Ohashi e Leão (2005) sementes de morototó conseguem expressar o seu máximo potencial germinativo quando armazenadas em períodos de até de 3 meses, a partir dai, ocorre um decréscimo acentuado no valor germinativo. No estudo em questão, as sementes se mantiveram armazenadas por um período de 1 ano e 9 meses antes de sua utilização.

Anastácio et al. (2010) estudando a quebra de dormência de sementes de morototó recém colhidas em diferentes estágios de maturação, verificaram índices abaixo de $59 \%$ de germinação. Em outro estudo realizado com sementes dessa espécie, verificou-se que após 11 meses de armazenamento o índice de germinação caiu para 33\% (OHASHI; LEÃO 2005).

Falar sobre o período em que as sementes conseguem se manter viáveis durante o armazenamento se faz importante, pois a partir dessas informações é possível definir uma estratégia de manutenção da qualidade da semente juntamente ao tratamento ideal para quebrar a sua dormência.

Além do período de armazenamento, outro fator limitante à germinação é o teor de água que a semente apresenta no momento do armazenamento Ohashi e Leão (2005). Segundo os autores, o teor de água recomendado para essa espécie durante o armazenamento, seria em torno de $10 \%$. Os testes realizados para avaliar o teor de água das sementes do presente estudo mostraram que estas 
apresentavam $6,54 \%$ de teor de água, sendo dessa forma, um valor muito inferior ao recomendado.

O baixo teor de água pode ter afetado à qualidade das sementes no que diz respeito à rápida reorganização das membranas quando essas são novamente umedecidas para se iniciar a germinação. O material usado nesse experimento passou por um longo período de armazenamento, e aliado ao fato de que estas sementes apresentavam teor de agua reduzido, quando se deu inicio aos tratamentos, a absorção de água por elas foi consequentemente rápido, impedindo, portanto, que houvesse tempo suficiente para a correta reorganização das membranas, causando assim, danos à qualidade fisiológica da semente (MARCOS FILHO, 2015). Segundo Marcos Filho (2005), diferenças muito acentuadas entre os potencias hídricos da semente, podem acarretar grandes problemas, devido a entrada de água muito rápida, especialmente, naquelas menos vigorosas ocasionando danos por embebição e rupturas da estrutura celular.

Além do que já foi apresentado acima, uma das variáveis estudadas foi o peso de mil sementes, que para o morototó foi de $14,71 \mathrm{~g}$, sendo este valor considerado aceitável para a espécie. De acordo com Ohashi e Leão (2005) o peso de mil sementes dessa espécie pode variar entre 10,1 a 16,9g, sendo possível inferir que a não germinação das sementes utilizadas nesse experimento, não ocorreu pelo fato de existirem sementes vazias, pois o peso de mil sementes da amostra estudada estava com valores dentro dos recomendados para a espécie. Amaro et al. (2015) avaliando peso de mil sementes na cultura do feijão não conseguiu verificar eficiência quanto ao resultado do teste, contrário do observado no presente estudo.

Além disso, foi possível verificar que a não germinação das sementes não foi influenciada apenas pelos tratamentos aplicados a elas, o ambiente e o tempo em que essas sementes estiveram armazenadas causaram grande influência nos resultados finais. Assim como, em sementes de morototó, outras espécies também sofrem alto índice de deterioração quando submetidas a longos períodos de armazenamento, sementes de Passiflora mucronata recém-colhidas também possuem alto potencial germinativo, mas com o passar do tempo o índice de germinação é reduzido, chegando a zero a partir dos quatro meses de armazenamento (SANTOS et al., 2012).

\section{CONCLUSÕES}

Os tratamentos usados na avaliação da quebra de dormência tegumentar em sementes de Schefflera morototoni não são eficientes em sementes armazenadas por longo período.

\section{REFERÊNCIAS}

ABDO, M. T. V. N.; FABRI, E. G. Transferência de tecnologia: guia prático para quebra de dormência de sementes de espécies florestais nativas. Pesquisa \& Tecnologia, v. 12, n. 2, Jul- Dez 2015. Disponível em: $<\mathrm{http}$ ://www.aptaregional.sp.gov.br/acesse-os-artigos-pesquisa-e tecnologia/edicao2015/julho-dezembro-3/1670-tecnologia-guia-pratico-para quebra-de-dormencia-desementes-de-especies-florestais-nativas/file.html>.

ABREU, D. C. A.; PORTO, K. G.; NOGUEIRA, A. C. Métodos de Superação da Dormência e Substratos para Germinação de Sementes de Tachigali vulgaris L.G. Silva \& H. C. Lima. Floresta e Ambiente, v. 24, n.1, p. 2-10, 2017. Disponível 
em<http://hostarticleassets.s3.amazonaws.com/floram/5a70880d0e8825b53c5dfcc3/ fulltext.pdf>. doi:http://dx.doi.org/10.1590/2179-8087.071814

AMARO, H. T. R.; DAVID, A. M. S. S.; ASSIS, M. O.; RODRIGUE, B. R. A.; CANGUSSÚ, L. V. S.; OLIVEIRA, M. B. Testes de vigor para avaliação da qualidade fisiológica de sementes de feijoeiro. Revista de Ciências Agrárias, vol. 38, n.3, 2015. Disponível em: $<$ http://www.scielo.mec.pt/scielo.php?script=sci_arttext\&pid=S0871018X2015000300013>

ANASTÁCIO, M. R.; SANTANA, D. G.; OLIVEIRA, R. C.; BABATA, M.; OLIVEIRA, C. A. A. Maturação e qualidade física de frutos na germinação dos pirênios de Schefflera morototoni (Araliaceae). Ciência Florestal, Santa Maria, v. 20, n. 3, p. 429-437, 2010.2 Disponível <https://periodicos.ufsm.br/cienciaflorestal/article/view/2058.> em: http://dx.doi.org/10.5902/198050982058

ANDRADE, A.C.S.; LOUREIRO, B.M.; SOUZA, A.D. de O.; RAMOS, F.N. Quebra de dormência de sementes de sucupira-preta. Pesquisa Agropecuária Brasileira, v.32, n.5, p.465-469, 1997. Disponível em: < https://seer.sct.embrapa.br/index.php/pab/article/view/4673>

BISPO, N. da S.; FERREIRA, L. C. Escarificação mecânica, tratamento térmico e ácido giberélico na quebra de dormência de sementes de Annona crassiflora MART. Caderno de Ciências Agrárias, v. 10, n. 1, p. 13-17, 2018. Disponível em: $<$ https://periodicos.ufmg.br/index.php/ccaufmg/article/viewFile/10643/8625>

BRASIL. Regras para Análise de Sementes. Brasília, DF: Ministério da Agricultura, 360 Pecuária e Abastecimento, 395p. 2009.

CARVALHO, P. E. R. Espécies arbóreas brasileiras. Colombo: Embrapa Florestas, 2014. $1039 \mathrm{p}$.

CIPRIANI, V. B.; GARLET, J.; LIMA, B. M. de; ARANTES, V. T. Quebra de dormência e caracterização biométrica em sementes de Schefflera morototoni (Aubl.) Maguire et al. Espacios. vol. 37, № 31, p. 18, 2016. Disponível em: < https://www.revistaespacios.com/a16v37n31/16373118.html>

FERNANDES, V. J.; SOUZA, T. S.; GAZAL, V.; AGUIAR-MENEZES, E. L.; MENEZES, E. B. Floresta e Ambiente, v. 26, n.1, p. 2-10, 2019. Disponível em:< http://www.scielo.br/scielo.php?script=sci_arttext\&pid=S217980872019000100115\&l ng=en\&tlng=en $>$.doihttp://dx.doi.org/10.1590/2179-8087.056217

FERREIRA, D. F. Sisvar: a Guide for its Bootstrap procedures in multiple comparisons. Ciência e Agrotecnologia. vol.38, n.2, p. 109-112, 2014. Disponível em: $\quad<\quad h t t p: / / w w w . s c i e l o . b r / s c i e l o . p h p ? s c r i p t=s c i \_a r t t e x t \& p i d=S 1413$ $70542014000200001>$

LIEGEL, L.H. Didymopanax morototoni (Aubl.) Decne. \& Planch. (yagrumo macho). In: BURNS, R.M.; HONKALA, B.H. Silvics of North America: v.2 hardwoods. 
Washington: USDA. Forest Service, 1990. p.288-293. (USDA. For. Ser. Agriculture Handbook, 654).

LUCAS, R. R..; GOMES,G. C.; GUARINO, E. S.; FREITAS, T. C.; AMARAL, S. W.; SOUSA, L. P.; MIURA, A. K.; COSTA, C. J. Germinação de sementes de Myrsine coriacea (Primulaceae) submetidas a diferentes tratamentos para superação da dormência. Iheringia, Série Botânica, v. 73, n. 2, p.108-113, 2018. Disponível em: < https://isb.emnuvens.com.br/iheringia/article/view/566>

MAGUIRE, J. D. Speeds of germination-aid selection and evaluation for seddling emergence and vigor. Crop Science, vol.2, n. 2, p. 176-177, 1962.

MARCOS FILHO, J. Germinação. In: .Fisiologia de sementes de plantas cultivadas. Piracicaba. FEALQ, 2005. p. 197-252.

MARCOS FILHO, J. Fisiologia de sementes de plantas cultivadas. Piracicaba: FEALq, 2015. 659p

MEDEIROS, A. C. S. Aspectos de dormência em sementes de espécies arbóreas. Colombo: Embrapa Florestas, 2001. 12p. (Circular Técnica, 55).

MESQUITA, A. J. B. de; FAGUNDES, J. M.; DELGADO, J. dos S. G. Influência da passagem pelo trato digestório de aves no processo germinativo de sementes de Schefflera morototoni (Aubl.) Maguire, Steyerm. \& Frodin (Araliaceae) coletadas no município de Jardim/MS. Instituto Federal de Educação, Ciência e Tecnologia de Mato Grosso do Sul - Campus Jardim, p.48, 2016. Disponível em: <http://2017.febrace.org.br/virtual/2017/BIO/174/>

OHASHI, S. T.; LEÃO, N. V. M. Morototó Schefflera morototoni (Aubl.) Maguire, Steyern. \& Frodin. Informativo Técnico Rede de Sementes da Amazônia, n. 12, 2005. Disponível em: < https://www.inpa.gov.br/sementes/iT/12_Morototo.pdf >

PEREIRA, D. S.; ARAÚJO, D. G.; SIMÕES, P. H. O.; PALHETA, L. F.; CORREIA, R. G. Quebra de dormência em sementes de Tachigali myrmecophila (Ducke) Ducke. Enciclopédia Biosfera, v. 11, n. 22, p. 2576 - 2588, $2015 .<$ http://www.conhecer.org.br/enciclop/2015c/agrarias/Superacao\%20Dormencia.pdf>

ROCHA, A. P.; MATOS, V. P.; SENA, L.H. M.; PACHECO, M. V.; FERREIRA, R. L. C. Métodos para superação da dormência em sementes de Garcinia gardneriana (Planch. \& Triana) Zappi. Ciência Florestal, v. 28, n. 2, p. 505-514, 2018. Disponível em: $\quad$ <https://periodicos.ufsm.br/cienciaflorestal/article/view/32031>.doi: http://dx.doi.org/10.5902/1980509832031

SAMPAIO, M. F.; COUTO, S. R.; SILVA, C. A.; SILVA, A. C. A.; SILVA, A. A. S.; TEIXEIRA, A. L. Influência de diferentes substratos associados a métodos de superação de dormência na germinação e emergência de sementes de jatobá (Hymenaea courbaril L.)

Revista Farociência, v. 2, n. 1, p 13-27. 2015. Disponível em<http://www.faro.edu.br/farociencia/index.php/FAROCIENCIA/article/view/94/97> 
SANTOS, de T. M.; FLORES, P. S.; OLIVEIRA, S. P. de; SILVA, D. F. P. da; BRUCKNER, C. H. Tempo de armazenamento e métodos de quebra de dormência em sementes do maracujá-de-restinga. Revista Brasileira de Agropecuária Sustentável, v. 2, n.1., p.26-31, julho, 2012. Disponível em: < https://www.alice.cnptia.embrapa.br/bitstream/doc/951753/1/24642.pdf> 